\title{
Gameplay as Learning: The Use of Game Design to Explain Human Evolution
}

\author{
Xavier Rubio-Campillo \\ University of Edinburgh and Murphy's Toast Games
}

\begin{abstract}
Video games are one of the most engaging media at our disposal to communicate knowledge. They offer a unique combination of interaction and storytelling that allows players not only to observe virtual worlds but also to experiment with these imagined universes in ways that cannot simply be matched by any other media.

This potential is explained by the fact that the player needs to take an active role inside the recreated world. The world should always be crafted to strengthen game mechanics and this requirement presents a challenge to anyone that wants to use games for archaeological outreach; the most scientifically accurate version of the past will be meaningless if the story, characters and dynamics of the game cannot capture the interest of the player.
\end{abstract}

How to cite this book chapter:

Rubio-Campillo, X. 2020. Gameplay as Learning: The Use of Game Design to Explain Human Evolution. In: Hageneuer, S. (ed.) Communicating the Past in the Digital Age: Proceedings of the International Conference on Digital Methods in Teaching and Learning in Archaeology (12-13 October 2018). Pp. 45-58. London: Ubiquity Press. DOI: https://doi.org/10.5334/bch.d. License: CC-BY 4.0 
The need for engaging experiences suggests that educational video games should never forget the basic requirement that any game needs to be fun. However, the dialogue between these two parallel goals poses some unique questions: what are the best approaches to combine learning with engagement? How does the goal of scientific dissemination affect gameplay? Can an educational game even compete with high-budget projects while seeking for players' interests?

We explore here how game design provides tools to overcome these challenges exemplified by the case of Ancestors: Stories of Atapuerca. This project aimed at presenting recent discoveries at the UNESCO World Heritage archaeological site of Atapuerca (Spain). The discussion on the game design principles used for this initiative highlights possible ways to improve the design of video games purposely created for scientific communication on human evolution.

\section{Keywords}

Digital Learning, Video Games, Archaeological Outreach, Game Design, Prehistory

\section{Introduction}

Video games have become the most important 21st-century cultural industry in terms of both audience size and economic activity. One of the main reasons for this success is that they are able to open powerful windows to new or past worlds thanks to the combination of embodiment and interactivity they provide (Slater \& Wilbur 1997). These two elements generate a strong cognitive link between the player and the experience; games are the only media where character actions are referred in the first person: 'I defeated the enemy', 'I died', 'I am moving to this city'. The strong sense of embodiment does not happen in other media because it requires a high degree of interactivity and immersion that is simply not possible while reading a book or watching a movie.

The way a video game is approached by a player is also unique. In essence, a game is a problem waiting to be solved. The structure of any game is organised as a sequence of increasingly difficult challenges that the player needs to solve using an explicit set of possible actions; this player will engage with a learning process for a simple yet powerful reason: it is the only way to achieve success in the game. Game challenges are based on abstract mechanics that can be enriched through background and narrative, which sometimes can play a major role within the player's experience. Archaeology is a popular source of inspiration for creating these game elements, but the relation between both worlds is still not properly explored. How are archaeologists and their activities presented to the public? Is scientific and historical accuracy relevant 
for game creators? How is the past experienced and perceived in the worlds they create?

Mainstream games such as Uncharted (Naughty Dog, 2007-2016) and Tomb Raider (Core Design \& Crystal Dynamics, 1996-2016) depict archaeologists in a way that is similar to other popular media and they use Indiana Jones as their main inspiration (Holtorf 2007: 62-63; Meyers Emery \& Reinhard 2015; Reinhard 2018: 62-88). The stereotype of the treasure hunter is complemented by mechanics focused on (1) exploration of mysterious ruins, (2) search and looting of mythical artefacts and (3) confrontation with powerful enemies. These products define the relation to archaeology adopted by a majority of games: to recreate the past in a way that reinforces the game mechanics and storytelling irrespective of its accuracy. The perspective is reasonable for a fictional product, but it has limited value as a pedagogical resource; it generates simplistic portrayals incapable of capturing the complexity and richness of past societies (Chapman 2012; Rejack 2007).

On the other hand, games classified as educational are typically focused on transmitting contents over designing a compelling experience. As a consequence, they are not as engaging as other products and are discarded by a majority of players beyond their compulsory use in the classroom (Squire 2008; Klopfer, Osterweil \& Salen 2009). The emphasis on heavy educational content combined with basic game mechanics (known as edutainment) is based on the false assumption that learning is boring, so games are used as a device to 'sweeten the pill' (Resnick 2004); by doing so these initiatives do not exploit the essential trait discussed above: beating a game is always a learning process.

Is there any way to blend both goals? A project following this design philosophy is a challenge because it would have to follow two different sets of requirements: (1) to create an engaging playing experience and (2) to transmit specific contents that may be complex to assimilate. These goals are often seen as opposite: either a game is fun or it is educational. We discuss here an alternative approach to achieve both goals: game design should be the main pedagogical tool precisely because any playful experience is a puzzle that requires learning to be solved (Schell 2014). In essence, the process of playing itself is a learning experience that may be used to discover the past in innovative and surprising ways.

This work explores this third approach in the context of archaeological outreach. The next section presents the general setting of Ancestors: Stories of Atapuerca. Ancestors is a pedagogical project created to promote outreach on human evolution. The third section discusses the relation between the game design of Ancestors and learning outcomes related to human evolution; we focus here on four common game design topics often overlooked by educational games: theme, lore, environmental narrative and game mechanics. The chapter concludes with a summary on how this innovative approach to video games as learning devices can improve the impact of scientific outreach activities within our society. 


\section{Ancestors: Stories of Atapuerca}

The construction of a railway line at the Sierra de Atapuerca in the mid-20th century revealed the existence of abundant archaeological material (Carbonell et al. 2014). The excavations carried out over the last four decades across the area have allowed us to gain a critical understanding of Palaeolithic Europe and human evolution: evidence suggests that at least four different groups of hominins lived in Atapuerca over a timespan of one million years (Homo antecessor, Homo heidelbergensis, Homo neanderthalensis and Homo sapiens).

The continued presence of hominin groups around Atapuerca can be explained by its strategic location: the mountain range is located at the crossroads between two rivers (the Duero and Ebro) and at the boundary between different ecosystems. Any group living at the Sierra would be able to access water resources while controlling areas of prairie that would work as perfect hunting grounds. The archaeological complex of Atapuerca is so critical to understand our past that in 2000 it was declared a UNESCO World Heritage Site.

The interest in the landscape of Atapuerca and the long human history that it witnessed made it an ideal setting for a video game on human evolution. The project 'Atapuerca - Evolución. Videojuegos Educativos' was led by the DIDPATRI research group from the University of Barcelona and it aimed at presenting the recent discoveries at this site with video games.

The primary output of this initiative was Ancestors: Stories of Atapuerca (Murphy's Toast Games, 2018). Ancestors is a simulation/strategy game where the player takes the role of the leader of a hominin clan living in Atapuerca. The experience is structured as a set of stories told by an elder Homo sapiens to her group, as seen in Figure 1. This setting linked all these stories (i.e. game scenarios) depicting different hominin groups through a common starting point. This elder preface to each mission also emphasised the importance that oral tradition had to prehistoric human groups. Each of the four stories released until now tells the legend of an ancestor of the group in a different era, thus exploring the differences on landscape, technology and biology across hominin groups.

The first story is a tutorial designed to allow the player to learn what actions can be used to lead the clan. It can be moved across different camps located at the Sierra de Atapuerca and each of these camps offers different activities, as can be seen in Figure 2. The range of actions include tasks that would be common for Palaeolithic peoples (e.g. hunt animals, gather resources and plants, make tools...). The remaining three stories set out different scenarios where a careful planning of actions, resources and timing will allow the player to achieve a sequential list of goals and advance the story until its ending.

The player needs to achieve these goals by performing required activities while keeping a food reserve. This food reserve works as the health bar of the group: if it ever reaches zero then the clan is forced to migrate and leave Atapuerca for some time. The final score of a story is based on the number of times the player's clan has been forced to migrate. 


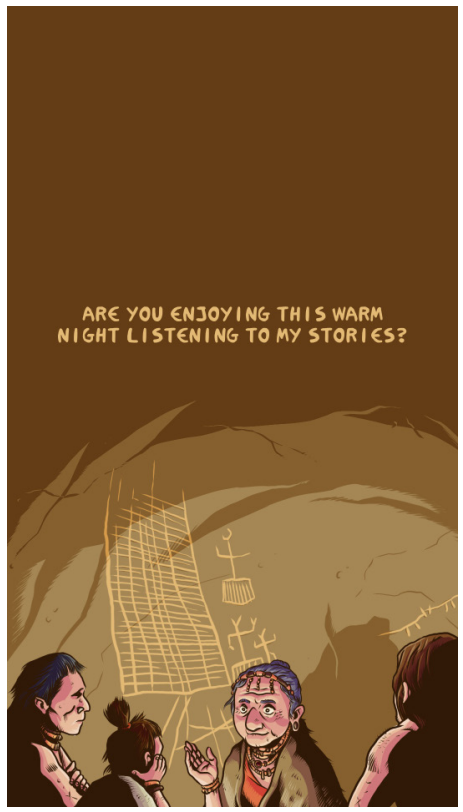

Figure 1: Storytelling structures the different episodes of the game. CC-BY SA 4.0 Murphy's Toast Games.

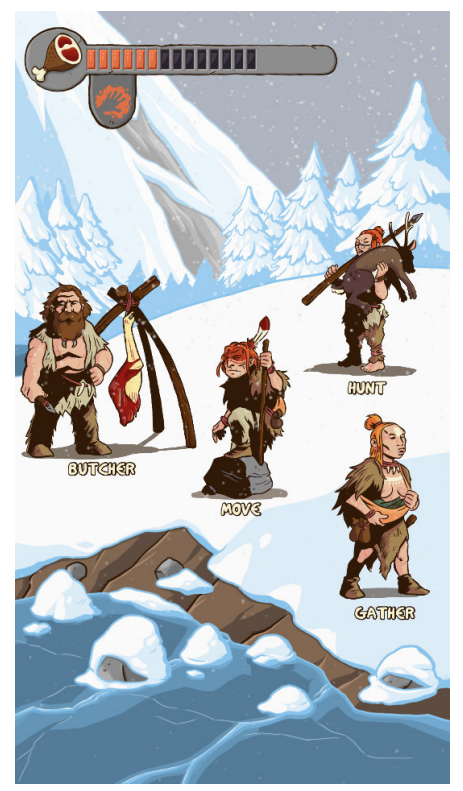

Figure 2: Each character on the camp defines a different activity that can be performed by the player. CC-BY SA 4.0 Murphy's Toast Games. 


\section{Game design as a learning device}

Game-based learning is currently recognised as an efficient approach to acquire new skills and knowledge due to its high cognitive gain. While there exist current debates on the difficulties of quantifying this gain, a large corpus of literature suggests that the principles of embodiment, interactivity and problem-solving are key to understanding the effectiveness of games for cognitive learning (see Wilson et al. 2009 for a review).

This learning process can be generally split into three phases (Vogel et al. 2006). Firstly, the learner needs to acquire a specific set of knowledge. Secondly, they need to organise the acquired knowledge by grouping units of information and map these units into mental models. Finally, the learner should be able to devise strategies to apply the organised knowledge to new situations.

The inherent nature of games as virtual worlds explored through problemsolving induces any player to closely follow these three steps if she wants to beat the game. However, this is only true if the learning outcomes for a specific game are integrated within the learning strategies of the game itself (Gee 2005). This is arguably missing in most educational games because they mainly rely on the first step of the process; even large-scale commercial products such as Assassin's Creed Origins: Discovery Tour do not follow this approach. In this case, the player can experience Hellenistic Egypt by taking part in a set of virtual guides to a diversity of aspects of daily life and architecture of the period. While this can be fascinating, the tours do not use any of the game mechanics that made the Assassin's Creed franchise popular, thus inhibiting any application of the acquired knowledge (i.e. the third step of the learning process).

These three steps can only be fulfilled by using game design principles. Game design can be broadly defined as the process of conceiving and designing the rules and structure of a game (Salen, Tekinbaş \& Zimmerman 2004). During the development of Ancestors the team identified four main aspects of game design that could be used to integrate educational goals with gameplay: (1) the underlying theme of the game, (2) the lore or background of the game's world, (3) the use of environmental narrative and (4) game mechanics for problem-solving.

\section{Theme}

The theme of a game is the unifying concept that permeates all the aspects of the artistic work. It is often an abstract concept (e.g. friendship, treason or hope) that allows game developers to focus the entire creative process of a video game into the most essential traits that should be present in the product. The theme is often not explicitly mentioned, and several players would not even recognise the theme of their preferred games. However, this concept helps to focus the myriad of decisions taken during design because they should always reinforce the theme as a means to provide a cohesive experience. 
Creators have absolute freedom on the choice of the theme and for this reason several topics crossing the archaeological discipline could be potentially chosen as the primary theme of a game. These concepts could be rather abstract and accommodate current debates of the discipline (e.g. individuality vs community, social change, agency), but they could also be much more specific, as was the case in Ancestors.

The archaeological site of Atapuerca is unique because it has a very long and almost complete sequence of human occupation across hundreds of thousands of years. We wanted to integrate a variety of hominin groups in the game and include at least stories of Homo antecessor and Homo neanderthalensis. Moreover, all stories would be told from the perspective of a Bronze Age group of Homo sapiens so constant human occupation seemed to be a recurrent topic. A theme that could strengthen the temporal dimension was the transcendence of human life: several generations will pass across thousands of centuries, but the essential traits that makes us human are always present, even across groups. The theme would be present in all aspects of the game, as previously discussed, and even the game menus were inspired by this theme, as can be seen in Figure 3.

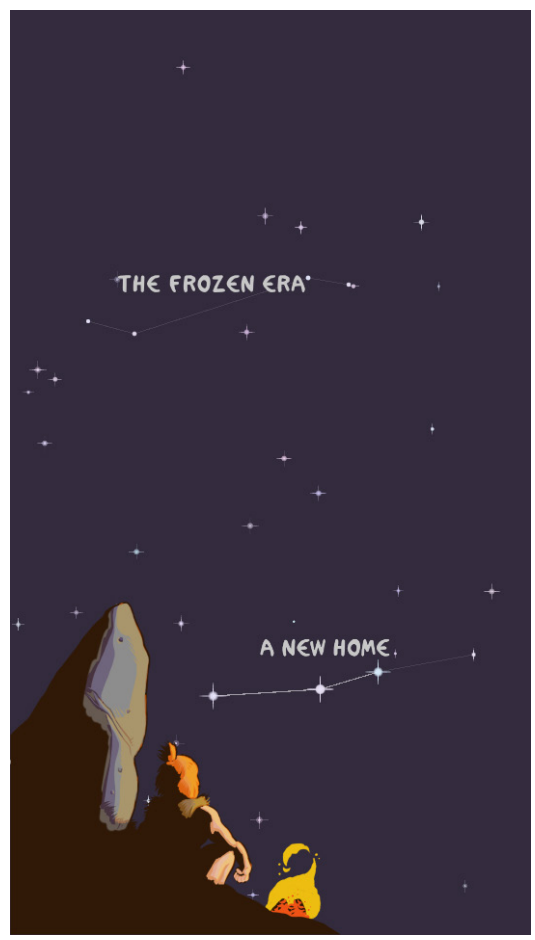

Figure 3: The main menu was uniquely designed to reinforce the theme of transcendence: the human groups that the player leads lived thousands of years apart from each other, but all of them watched the same stars on a clear night sky. CC-BY SA 4.0 Murphy's Toast Games. 


\section{Lore and exposition}

The lore of an imaginary world is the collection of facts, belief and knowledge crafted to provide context to the narrative. It is transmitted to the audience through the process of exposition, which may take a variety of forms, the most common being dialogue between characters, item descriptions, diary entries and cut scenes.

There is a clear parallel between the lore of a fantasy-themed game and the introduction of knowledge in an educational game. Most educational games use text-based exposition because it is easy to make and it closely resembles classical educational media such as textbooks. While this passive approach to game content may be effective, it often works against the interactive nature of the media.

Ancestors had to provide the lore of a prehistorical period without written records and scarce evidence on the existence of language. This scenario was a double-edged sword; on the one hand, it made knowledge transmission difficult because several aspects of Palaeolithic daily life are speculative; on the other hand, it allowed the team to develop new lore that contributed to an improved gameplay while still based on archaeological evidence.

The oral-based story setting was the main exposition mechanism of the game. The approach allowed us to reinforce the theme of transcendence by integrating the different groups into a common background. This cultural framework was based on myths and legends tailored to the specifics of the archaeological site of Atapuerca. For example, the mountain range itself took an almost mythical status as homeland and sanctuary of the clan that the player would be controlling during the entire game. This approach justified the 'game over' mechanism based on migration; it also strengthened the role that both territory and mobility played for prehistoric peoples.

\section{Environmental narrative}

The narrative of a simulation video game is typically secondary compared to other genres because this genre relies on emergent narratives generated by the player's own decisions. However, an engaging story can be used to raise the interest of the experience towards beating the game as a way to know how the story ended and what happened to the characters. In Ancestors we decided to use a mixed approach based on four independent stories taking place on different moments of Atapuerca's timeline. Each story is developed as a list of goals or main quests that need to be achieved before moving onwards. The narrative unfolds through the achievement of these goals and for this reason it provides a strong motivation for success: if the player wants to know what happened to the group then she will have to beat the game.

One aspect of video game storytelling that revealed particularly effective for scientific outreach is the use of environmental narrative elements. Environmental 
narrative uses visual and sound cues to reinforce the main story through a number of small details that provide coherence to the game's universe. This approach allowed us to integrate recent findings on human evolution in the game, including:

- Neanderthal use of tattoos, clothing and body decoration, as seen in Figure 2 (Zilhao et al. 2010).

- Characterisation of plants and animals based on existing evidence.

- Presence of children and elderly people in Palaeolithic groups, which are often invisible in video games.

- No assumptions on sex-based roles as the game alternated males and females for each activity within different groups.

- The cave paintings found in the 'Galería del Sílex' (Bronze Age) were used as the background of the Homo sapiens group (Diez et al. 2003).

Environmental narrative proved to be an efficient way of adding content to the game while avoiding the abuse of text-based exposition. The approach may be more indirect as players would never notice some of these subtle details, but it generates a scientifically accurate picture of Palaeolithic life while breaking common stereotypes seen in popular culture.

\section{Mechanics}

Game mechanics are the processes available to the player to interact with the game world (Sicart 2008). Any player needs to learn and master these mechanics during gameplay because it is a requirement to solve the problems introduced over the game.

Ancestors's game mechanics were based on activities summarising the essential traits of the hunter-gatherer lifestyle: hunt, make tools, gather resources, move camp etc. All of these activities could be undertaken using a common user interface, as seen in Figure 4, but each of them was unique in terms of options, requirements and outcomes.

Hunting was the task that focused the development team's efforts. Early testing with both high-school students and adults suggested that this activity should be one of the most important game mechanics of the game; feedback suggested that players were expecting hunting to be fun because it is a common mechanic in several commercial video games such as Red Dead Redemption 2 or the Monster Hunter franchises. The team decided to develop a specific mini game for the hunting activity based on a risk vs cost dilemma: should I go for the larger animals or stick to the ones that are easier to catch? Should I organise a large and expensive hunting party or risk it with a smaller group?

A random event system was also implemented to bring life to the world beyond the player's clan. Every time the player moves camp there is a chance than an event will happen; two options are then provided and the player needs 


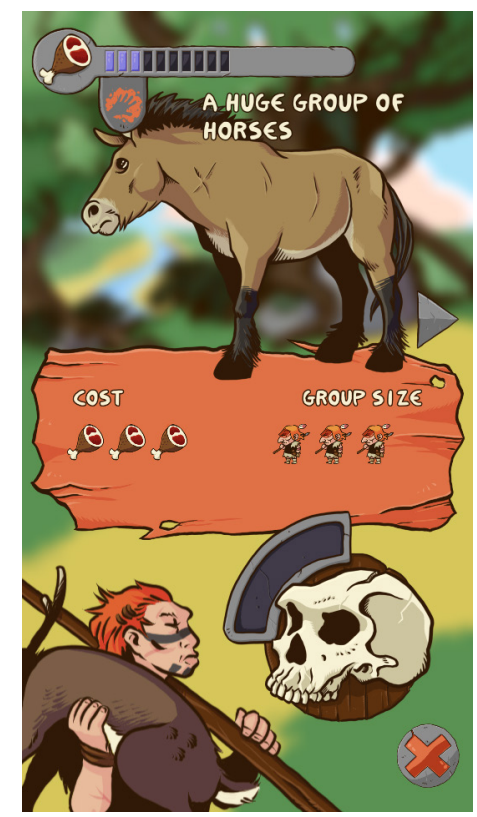

Figure 4: In the hunting activity the player needs to choose the prey and the size of the group (larger groups will require more tools and food). CC-BY SA 4.0 Murphy's Toast Games.

to choose which event will actually happen (see Figure 5). The effect of these events can be quite diverse and the player needs to think which one will provide more benefits (or less damage). Events are text-based and for this reason it was a simple yet effective way to enrich gameplay with other clans, climate change, animal migration or bits of agency.

\section{Concluding remarks}

Ancestors: Stories of Atapuerca was freely released during the autumn of 2018 in Google Play and Apple Store. The number of downloads (over 25k in six months) and the high average rating highlight the success of outreach initiatives grounded on video games. This archaeological project joins other experiences in a diversity of fields such as Herald for History (van der Schilden \& Heijltjes 2017) or Never Alone for Anthropology (Cook Inlet Tribal Council 2017) to suggest that there is a suitable path to design engaging experiences at the crossroads between pure entertainment and games as pure education. These transformational games (McGonigal 2011; Schell 2014) promote critical thinking and at the same time they are capable of interesting the player beyond 


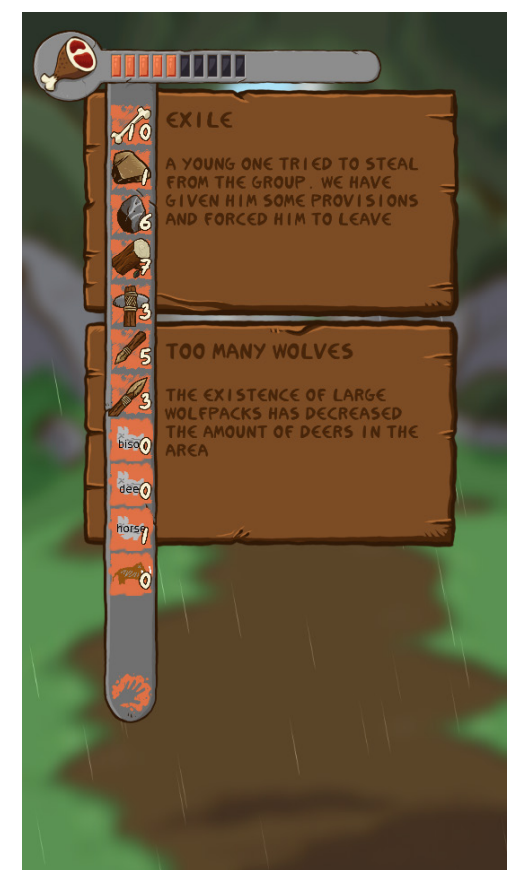

Figure 5: Events can have short- or long-term consequences on the world's state. CC-BY SA 4.0 Murphy's Toast Games.

the educational goals. At their core, transformational games apply common game design elements developed in the industry with a different perspective; they show that it is possible to generate engaging experiences while contributing to a new goal: to enrich the vision of the players about the world that surrounds them and, in the case of Ancestors, about the past of our species.

The first steps of video gaming during the 20th century offered a limited diversity of themes and topics to a restricted audience. At present the genre and topics treated by video games are as diverse as the community of gamers in terms of gender, age, interests and preferences. As a consequence, video game design is immersed in a transition phase towards maturity where unique and original language, narrative and mechanics are being introduced by a large number of small-sized projects. At the same time, the explosion of digital platforms such as Steam, the Apple Store and Google Play has simplified the distribution of any video game that can be now played by anyone with internet access (Rubio-Campillo 2013).

This combination of cultural innovation and ease of distribution is a perfect setting to try new ideas on the communication of archaeological knowledge to the main public; it is in our hands to create better cultural products able to promote engaging and critical approaches to our past, present and future. 


\section{Acknowledgements}

The author wants to thank the ATA-EVE and Murphy's Toast Games teams for their invaluable contribution to this project. ATA-EVE was funded by the BBVA foundation programme on digital humanities. Ancestors can be freely downloaded for iOS and Android from Murphy's Toast Games official website at http://www.murphystoastgames.com/sheet.php?p=ancestors.

\section{References}

Carbonell, E., Huguet, R., Cáceres, I., Lorenzo, C., Mosquera, M., Ollé, A., Rodríguez, X.P., Saladié, P., Vergès, J.M., García-Medrano, P. and Rosell, J. (2014). Sierra de Atapuerca archaeological sites. Pleistocene and Holocene hunters-gatherers in Iberia and the Gibraltar Strait. In: R.S. Ramos, ed., Pleistocene and Holocene Hunter-Gatherers in Iberia and the Gibraltar Strait: The Current Archaeological Record, Burgos: Universidad de BurgosFundación Atapuerca, pp. 534-560.

Chapman, A. (2012). Privileging form over content: Analysing historical videogames. Journal of Digital Humanities, 1(2): 1-2.

Cook Inlet Tribal Council (2017). Storytelling for the next generation: How a non-profit in Alaska harnessed the power of video games to share and celebrate cultures. In: A. Mol, C. Ariese-Vandemeulebroucke, K. Boom and A. Politopoulos, eds, The Interactive Past: A Book on Video Games and Archaeology, Leiden: Sidestone Press, pp. 21-32.

Diez, M.G., i Uixan, J.M., Merino, M.M. and Martínez, A.O. (2003). Dates for rock art at a Bronze Age sanctuary at the Galería del Sílex cave. Antiquity, 77(296). [online] Antiquity. Available at: http://www.antiquity.ac.uk/ projgall/diez296 [Accessed 6 May 2019].

Gee, J.P. (2005). Learning by design: Good video games as learning machines. E-learning and Digital Media, 2(1): 5-16.

Holtorf, C. (2007). Archaeology Is a Brand!: The Meaning of Archaeology in Contemporary Popular Culture, London: Routledge.

Klopfer, E., Osterweil, S., Salen, K. (2009). Moving Learning Games Forward, Cambridge, MA: The Education Arcade.

McGonigal, J. (2011). Reality Is Broken: Why Games Make Us Better and How They Can Change the World, London: Penguin.

Meyers Emery, K. and Reinhard, A. (2015). Trading shovels for controllers: A brief exploration of the portrayal of archaeology in video games. Public Archaeology, 14(2): 137-149.

Reinhard, A. (2018). Archaeogaming: An Introduction to Archaeology in and of Video Games, New York: Berghahn Books.

Rejack, B. (2007). Toward a virtual reenactment of history: Video games and the recreation of the past. Rethinking History, 11(3): 411-425. 
Resnick, M. (2004). Edutainment? No thanks. I prefer playful learning. Associazione Civita Report on Edutainment, 14: 1-4.

Schell, J. (2014). The Art of Game Design: A Book of Lenses, Boca Raton, FL: AK Peters/CRC Press.

Rubio-Campillo, X. (2013). El pasado en tu sofá: juegos de simulación histórica en entornos computacionales portables. Heritage \& Museography, 13: $55-62$.

Salen, K., Tekinbaş, K.S. and Zimmerman, E. (2004). Rules of Play: Game Design Fundamentals, Cambridge, MA: MIT Press.

van der Schilden, R. and Heijltjes, B. (2017). Herald: How Wispfire used history to create fiction. In: A. Mol, C. Ariese-Vandemeulebroucke, K. Boom \& A. Politopoulos, eds, The Interactive Past: A Book on Video Games and Archaeology, Leiden: Sidestone Press, pp. 73-82.

Sicart, M. (2008). Defining game mechanics. Game Studies, 8(2). [online] Available at: http://gamestudies.org/0802/articles/sicart [Accessed 6 May 2019].

Slater, M. and Wilbur, S. (1997). A framework for immersive virtual environments (FIVE): Speculations on the role of presence in virtual environments. Presence: Teleoperators \& Virtual Environments, 6(6): 603-616.

Squire, K.D. (2008). Video games and education: Designing learning systems for an interactive age. Educational Technology, 48(2): 17.

Vogel, J.J., Vogel, D.S., Cannon-Bowers, J., Bowers, C.A., Muse, K. and Wright, M. (2006). Computer gaming and interactive simulations for learning: A meta-analysis. Journal of Educational Computing Research, 34(3): 229-243.

Wilson, K.A., Bedwell, W.L., Lazzara, E.H., Salas, E., Burke, C.S., Estock, J.L. and Conkey, C. (2009). Relationships between game attributes and learning outcomes: Review and research proposals. Simulation \& Gaming, 40(2): 217-266.

Zilhao, J., Angelucci, D.E., Badal-Garcia, E., d'Errico, F., Daniel, F., Dayet, L. and Zapata, J. (2010). Symbolic use of marine shells and mineral pigments by Iberian Neandertals. Proceedings of the National Academy of Sciences, 107(3): 1023-1028.

\section{Ludography}

Ancestors: Stories of Atapuerca (2018). Murphy's Toast Games. [iOS and Android].

Assassin's Creed: Origins (2017). Ubisoft Montreal [Multiple platforms].

Herald: An Interactive Period Drama (2017). Wispfire. Wispfire. [PC, MAC and Linux].

Monster Hunter series (2004-2018). Capcom. [Multiple platforms].

Never Alone (Kisima Innitchuya) (2014). Upper One Games. E-Line Media.

[Multiple platforms]. 
Red Dead Redemption 2 (2018). Rockstar Games. [Playstation 4 and Xbox One]. Tomb Raider series (1996-2018). Core Design \& Crystal Dynamics. Eidos Interactive \& Square Enix. [Multiple platforms].

Uncharted series (2007-2016). Naughty Dog. Sony Interactive Entertainment. [PlayStation 3 and PlayStation 4]. 